\title{
Sulfur Transfer Characteristics and Pyrolysis Simulation in the Coal Polygeneration Process
}

\author{
Yaqing Zhang, Jialong Zhu, Peng Liang \\ handong University of Science and Technology \\ Qingdao, 266590, China \\ liangpeng202@hotmail.com
}

\begin{abstract}
In the polygeneration process of coal pyrolysis/circulating fluidized bed (CFB) combustion, the sulfur transformation characteristics and a heat transfer, reaction, pyrolysis mathematical model for the non-isothermal coal particles has been studied. The results show that, the circulating ash was effective in capturing the gaseous sulfur. The sulfur fixed in ash was increased by the increase in pyrolysis temperature and the decreased in ash particle size. $\mathrm{CaO}$ and $\mathrm{Fe} 2 \mathrm{O} 3$ in circulating ash displayed significant effect of sulfur retention. The pyrolysis model calculated that, the maximum temperature difference between the core and surface of coal $(5 \mathrm{~mm})$ has reached $440 \mathrm{~K}$ at the bed height of $0.02 \mathrm{~m}$. The layer closer to the coal core has a higher but later peak value of the devolatilization rate. The temperature of pyrolysis gas and circulating ash is always close.
\end{abstract}

Keywords - Polygeneration; Circulating ash; Sulfur transformation; Heat transfer; Volatile evolution

\section{INTRODUCTION}

In recent years, the direct combustion of coal has been a great public concern because of its low energy conversion efficiency and serious air pollution [1].The circulating fluidized bed (CFB) combustion technology have been developed greatly for its better fuel flexibility, low pollution and load adjustability in recent years [2]. And this provides a base for the polygeneration technology of coal pyrolysis and CFB combustion to achieve the grading conversion of coal. High-temperature ash, which comes from the CFB boiler is used as solid heat carrier, mixed with coal is fed into the pyrolyzer simultaneously, getting gas and tar. The semi-coke produced in the pyrolyzer is returned to CFB boiler to provide electricity and heat [3]. Thus the utilization of coal with high efficiency and low emissions is realized.

Many researches have focused on the development of the pyrolysis/combustion polygeneration process [4][5]. However, a comprehensive understanding of the sulfur transfer and the pyrolysis volatile evolution characteristics in this process is still required. It has been confirmed that the existence of the inorganic mineral can influence the transformation of sulfur during coal pyrolysis and combustion [6][7][8]. But few studies were carried out on sulfur transformation characteristics of pyrolysis/combustion dual-process. As the circulating ash contains inorganic mineral and its chemical constituents are really complicated, it is essential to further investigate the transformation of sulfur in the polygeneration process of CFB combustion combined with coal pyrolysis. Considerable modeling works on coal pyrolysis have also been investigated [9][10]. The results of radial stratification of large particle pyrolysis models [11][12] show that, the larger coal particle had slower heating rate and devolatilization rate. Unfortunately, the models are inappropriate for the solid heat carrier pyrolysis because the heat transfer mechanism outside the coal surface considered only the heat radiation and heat convection. Liang et al. [13] reported an axial-dimensional numerical model for coal pyrolysis by solid heat carrier toward the moving bed, and he assumed that the coal particle was an isothermal body. However, the existence of temperature gradient as a result of internal thermal resistance of coal particles cannot be ignored. Therefore, a reasonable pyrolysis model of non-isothermal coal particles by circulating ash carrier toward the axial dimension of the moving bed is necessary.

In this study, the key technical factors and the transformation mechanism of residual and captured sulfur in char/ash during the combustion process were investigated. Based on the heat transfer theory of gas-solid-solid three phases, a reasonable pyrolysis model was established. The model can not only predict the internal heat conduction and devolatilization process of coal particles, but also analysis the temperature distribution of coal, pyrolysis gas, and ash downward the moving bed. This work will provide a theoretic foundation for the polygeneration technology of coal pyrolysis combined with CFB combustion.

\section{MATERIALS AND METHODS}

\section{A) Coal and ash samples}

High-sulfur Xinzhou (XZ) bituminous coal was employed to carry out the sulfur transfer experiments. Low-sulfur Shenmu (SM) bituminous coal was used for the model calculation of heat transfer. The XZ coal sample was crushed and sieved to $0.075-0.106 \mathrm{~mm}$. Table 1 shows the proximate and ultimate analyses of the two coals. Quartz sand and circulating ash were chosen as the solid heat carriers in this study. Table 2 shows the composition of circulating ash which was collected from a $75 \mathrm{t} / \mathrm{h}$ CFB boiler. 
TABLE 1 Proximate And Ultimate Analyses Along With Sulfur Contents (wt\%) of XZ and SM coal

\begin{tabular}{|c|c|c|c|c|c|c|c|c|c|c|c|c|}
\hline & \multicolumn{4}{|c|}{ Proximate analysis (ad) } & \multicolumn{5}{|c|}{ Ultimate analysis (daf) } & \multicolumn{3}{|c|}{ Sulfur content (daf) } \\
\hline & M & A & $\mathrm{V}$ & FC & $\mathrm{C}$ & $\mathrm{H}$ & $\mathrm{N}$ & $\mathrm{S}$ & $\mathrm{O}^{*}$ & $\mathrm{~S}_{\mathrm{p}}$ & $\mathrm{S}_{\mathrm{s}}$ & $\mathrm{S}_{\mathrm{o}}{ }^{*}$ \\
\hline $\mathrm{XZ}$ & 0.75 & 13.06 & 33.73 & 52.46 & 82.64 & 5.42 & 1.21 & 3.11 & 7.62 & 1.11 & 0.34 & 1.66 \\
\hline SM & 7.21 & 3.89 & 31.54 & 57.36 & 80.88 & 5.09 & 1.08 & 0.29 & 12.66 & - & - & - \\
\hline
\end{tabular}

* By difference; ad, air dry; daf, dry ash free; M, moisture; A, ash; V, volatile matter; FC, Fixed Carbon; $\mathrm{S}_{\mathrm{p}}$, pyritic sulfur; $\mathrm{S}_{\mathrm{s}}$, sulfate sulfur; $\mathrm{S}_{\mathrm{o}}$, organic sulfur.

TABLE 2 Ash Composition (wt\%) Of The Circulating Fluidized Bed Boiler

\begin{tabular}{rccccccccc}
\hline $\mathrm{Al}_{2} \mathrm{O}_{3}$ & $\mathrm{CaO}$ & $\mathrm{Fe}_{2} \mathrm{O}_{3}$ & $\mathrm{~K}_{2} \mathrm{O}$ & $\mathrm{MgO}$ & $\mathrm{Na}_{2} \mathrm{O}$ & $\mathrm{P}_{2} \mathrm{O}_{5}$ & $\mathrm{SO}_{3}$ & $\mathrm{TiO}_{2}$ & $\mathrm{SiO}_{2}$ \\
33.23 & 2.46 & 5.03 & 1.11 & 0.53 & 0.16 & 0.13 & 0.73 & 0.86 & 55.76 \\
\hline
\end{tabular}

\section{B) Apparatus and procedure}

The pyrolysis experiments were performed in a fixed-bed reactor, as shown in Fig. 1. Each time $5 \mathrm{~g}$ coal and $25 \mathrm{~g}$ ash were positioned into a quartz tube (length: $440 \mathrm{~mm}$, inside diameter: $19 \mathrm{~mm}$ ), and then the tube was placed into the temperature programmed furnace. The carrier gas used was $\mathrm{N}_{2}$ with a flow rate of $60 \mathrm{ml} / \mathrm{min}$. The heating rate was $10{ }^{\circ} \mathrm{C} / \mathrm{min}$ and the holding time was $10 \mathrm{~min}$. The released tar from the volatiles was cooled down and collected in a cold trap. Sulfur containing gases generated during coal pyrolysis were measured by gas chromatography, equipped with flame photometric detector. The sulfur contents in char and tar were determined by ZCL2003 sulfur determination analyzer. The contents of sulfate sulfur and pyritic sulfur were determined by GB/T 215-2003, and organic sulfur content was calculated by subtraction. In order to investigate the sulfur transformation characteristics in the CFB boiler of the polygeneration process, the combustion experiment of ash and char which obtained from the fixed-bed pyrolysis reaction were performed and compared with that of coals. In each run, $4 \mathrm{~g}$ ash (or $1 \mathrm{~g}$ char) was combusted with a $120 \mathrm{ml} / \mathrm{min}$ air flow. The heating rate was $15{ }^{\circ} \mathrm{C} / \mathrm{min}$ and the holding time was $90 \mathrm{~min}$ at the final temperature. The sulfur in combustion product was determined by ZCL2003 sulfur determination analyzer.

\section{C) TG-MS and XRD experiment}

The pyrolysis of $\mathrm{XZ}$ coal and the mixture of $\mathrm{XZ}$ and ash were performed in the thermogravimetric-mass spectrometry (TG-MS) system which is composed of a TG/TGA (Setaram Setsys-Evolution, Caluire, France) and a MS (Balzers Omnistar, Brügg, Switzerland). A sample of $15 \mathrm{mg}$ was placed in a ceramic crucible and heated from room temperature to $800^{\circ} \mathrm{C}$. at a heating rate of $30{ }^{\circ} \mathrm{C} / \mathrm{min}$. The flow rate of $\mathrm{N}_{2}$ is $80 \mathrm{ml} / \mathrm{min}$. The evolved gases were automatically analyzed by the MS. The electron impact source was tuned at $40 \mathrm{eV}$, and the mass spectra range was 0-300 amu. X-ray diffraction (XRD) patterns were collected on a D/max2500PC automatic powder X-ray diffractometer using $\mathrm{CuK} \alpha$ radiation at $200 \mathrm{~mA}$ and $40 \mathrm{kV}$. The XRD diffraction patterns were obtained in the range of $2 \theta$ between $10^{\circ}$ and $80^{\circ}$ at a scan speed of $5 \%$ min.

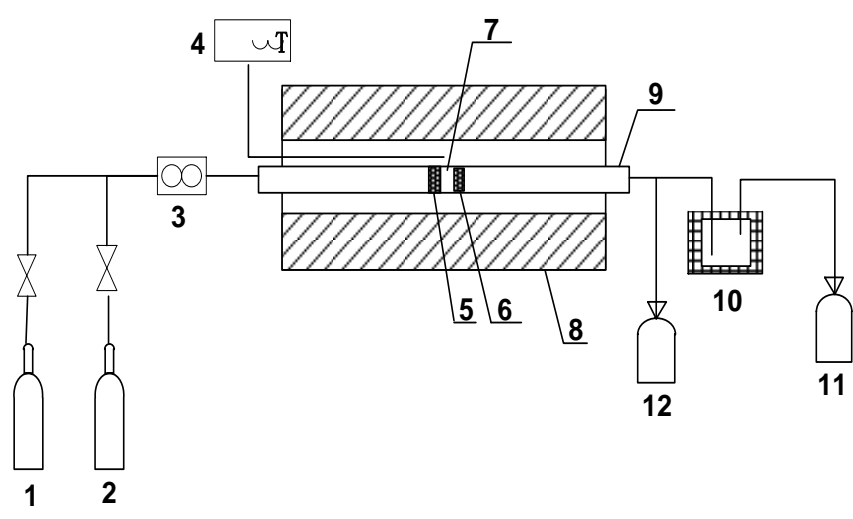

Fig. 1. Schematic diagram of the fixed-bed reaction equipment. (1) Nitrogen; (2) air; (3) mass flow controller; (4) temperature controller; (5) coal; (6) solid carrier.

\section{MATHEMATICAL MODEL OF PYROLYSIS BY ASH HEAT CARRIER}

\section{A) Model assumptions.}

The diagram of the model pyrolysis description is shown in Fig. 2. The coal coupled with high-temperature circulating ash is fed into the mixing section. As the mixed material moving downwards in the pyrolyzer, the coal particles are heated by ash and pyrolysis gas released from the under layer. When the coal particle temperature continues to rise, the pyrolysis gas is discharged from the outlet of the moving-bed pyrolyzer, while the ash and char are returned to the CFB boiler. Assumptions of the model simplification are as follows:

1) Ash particles are the inert spherical particles with no temperature gradient inside, only involved in heat exchanging rather than chemical reactions.

2) The spherical coal particles are surrounded by ash particles tightly. The characteristics of single coal particles can predict the characteristics of coal cluster in the same bed layer.

3) The moving-bed pyrolyzer is operated at a steady state, and the governing parameters do not change with time.

4) The calculation time is small enough to ensure little 
temperature change of the particles within a time step.

5) It is assumed that the particle size of coal remains unchanged. Ignore the diffusion process of the pyrolysis products evolved from the internal to external of the coal particles, as well as the secondary or multiple pyrolysis.

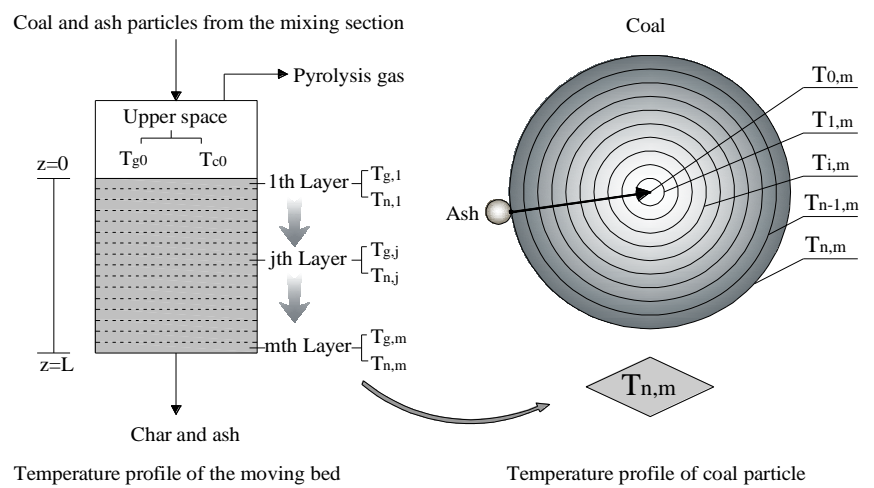

Fig. 2. Diagram of the model description.

\section{B) Mechanisms of heat transfer}

The coal-ash-pyrolysis gas three phases heat transfer involves complex mechanisms. Based on the assumptions, the mainly considered mechanisms in this study are as follows:

1) The thermal conduction equation between ash and coal particles can be described by

$d q_{c o d}=\lambda_{a} S_{c} R_{a c} \frac{T_{a}-T_{c}}{d_{p a}}$

2) Radiation heat transfer between ash and coal particles can be calculated using

$d q_{\text {rad }}=\beta \sigma \chi S_{c}\left(1-R_{a c}\right)\left(T_{a}^{4}-T_{c}^{4}\right)$

3) The convection heat transfer between pyrolysis gas and ash particles is presented as

$d q_{a g}=h_{a g}\left(S_{a}-S_{c} R_{a c}\right)\left(T_{a}-T_{g}\right)$

4) The convection heat transfer between pyrolysis gas and coal particles is given by the equation

$d q_{c g}=h_{c g} S_{c}\left(1-R_{a c}\right)\left(T_{g}-T_{c}\right)$

Therefore, the heat balance equations of the pyrolysis gas and ash are expressed as

$u_{s} A \frac{1-\varepsilon}{1+\theta} \rho_{c 0}\left(w^{*}-w\right) c_{p g} d T_{g}=d q_{a g}-d q_{c g}$

$u_{s} A \theta \frac{1-\varepsilon}{1+\theta} \rho_{a} c_{p a} d T_{a}=-d q_{c o d}-d q_{\text {rad }}-d q_{a g}$

The internal heat conduction equation of coal particles can be presented in the form of a spherical coordinate system:

$\rho_{c} C_{p c} \frac{\partial T}{\partial t}=\lambda_{c}\left(\frac{\partial^{2} T}{\partial^{2} r}+\frac{2}{r} \frac{\partial T}{\partial r}\right)-\rho_{c 0} \Delta \mathrm{H} \frac{\partial \omega}{\partial t}$

Boundary conditions

Surface of coal particle:

$\left.\lambda_{c} S_{c} \frac{\partial T}{\partial r}\right|_{r=R}=d q_{c o d}+d q_{r a d}+d q_{c g}$

$$
\text { Center of coal particle: }\left.\lambda_{c} S_{c} \frac{\partial T}{\partial r}\right|_{\mathrm{r}=0}=0
$$

C) Calculation method

Finite Difference Method (FDM) is applied to discretize the governing equations. The discrete algebraic equations are solved by Three Diagonal Matrix Algorithm (TDMA). The internal radial distribution of coal particles is divided into 10 layers.

\section{RESUlTS AND DisCUSSION}

\section{A) Sulfur transfer experiment}

Evolution of gaseous sulfur. The TG-MS curves of gaseous sulfur during pyrolysis are presented in Fig. 3. It can be seen from the figure that after the ash added, the evolution intensities of the four gaseous sulfurs are all significantly reduced. The above results have shown that ash has significant action of sulfur retention during coal pyrolysis.

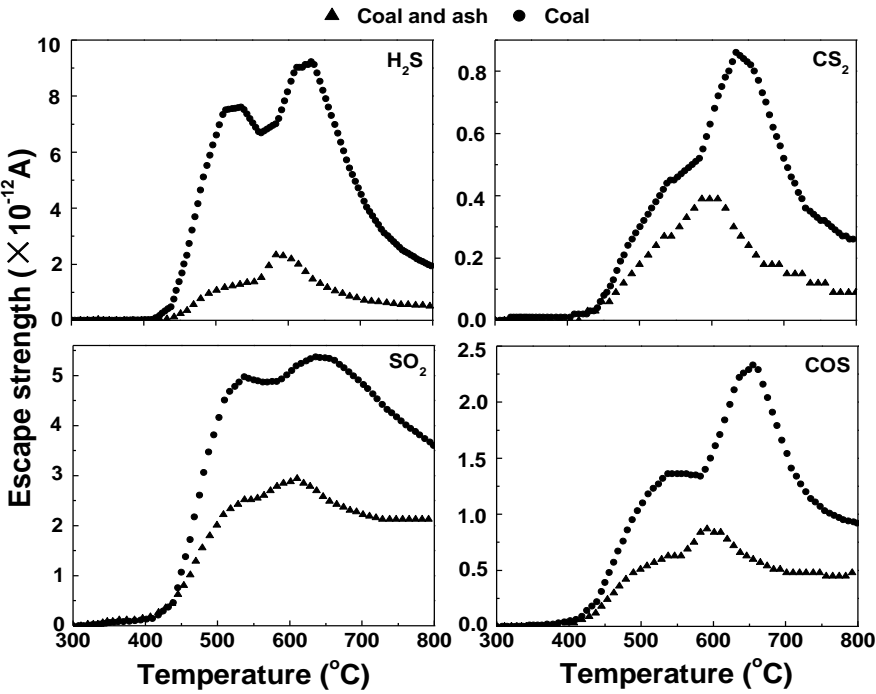

Fig. 3. TG/MS analysis of gaseous sulfur released during pyrolysis

Effect of pyrolysis Temperature on sulfur transformation. The effect of temperature on sulfur transformation during pyrolysis of SX coal was studied from 450 to $700^{\circ} \mathrm{C}$. Fig. 4 shows that ash can capture some of gaseous sulfur and the behavior of sulfur retention increases with the temperature. The effect of pyrolysis temperature on the forms of sulfur in char is shown in Fig. 5. It was suggested that pyrite sulfur was easily decomposed above $550^{\circ} \mathrm{C}$ with increasing temperature. The content of organic sulfur decreased with temperature up to $500^{\circ} \mathrm{C}$ and the sulfur were mostly labile organic sulfurs like thiols and disulphides [14]. It was also proved from Fig. 6 that pyritic sulfur can be transformed into organic sulfur above $500^{\circ} \mathrm{C}$. The reason for this phenomenon is possibly that the $\mathrm{H}_{2} \mathrm{~S}$ released by decomposition of pyrite will be trapped by char, when it diffuses away from the coal interface through pores of the matrix. In addition, coal pyrolysis process will produce a lot of closed voids, $\mathrm{H}_{2} \mathrm{~S}$ in the voids can react with organic matrix to form new organic sulfur. 


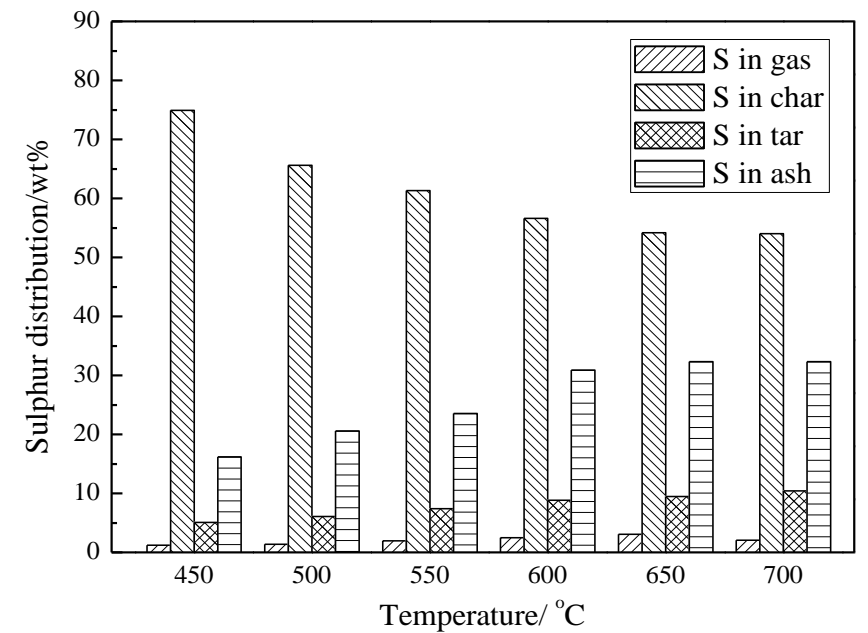

Fig. 4. Effect of pyrolysis temperature on sulfur distribution using CFB boiler ash carrier

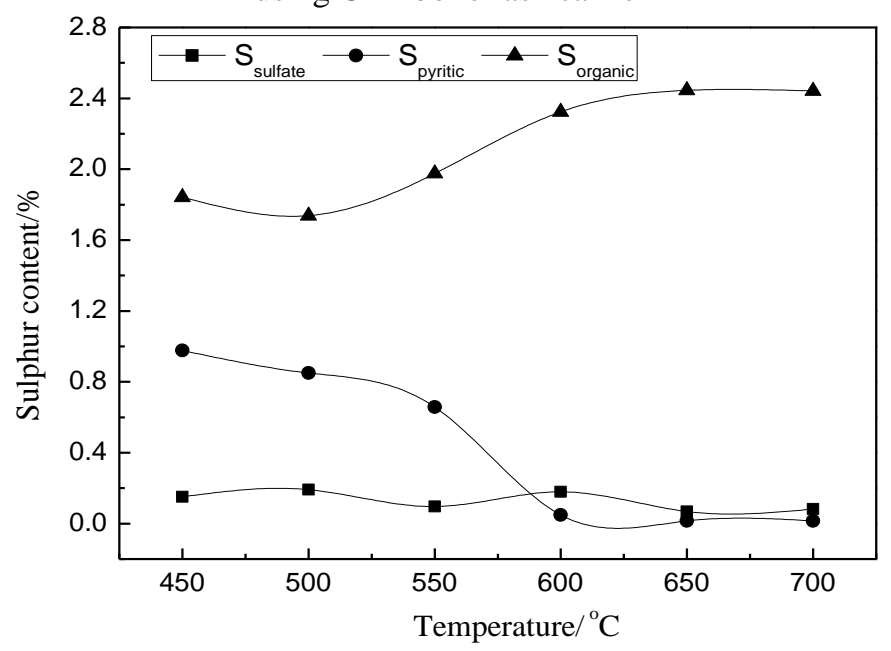

Fig. 5. The effect of pyrolysis temperature on the forms of sulfur in char

Effect of inherent and add inorganic matter on sulfur transformation. The retention of both organic and inorganic sulfur during coal pyrolysis is influenced by inorganic matter present in coal. It can be seen from Fig. 6 that sulfur released to gas showed an obvious increase after the inorganic matter removed. And the addition of $\mathrm{CaO}$ and $\mathrm{Fe}_{2} \mathrm{O}_{3}$ significantly reduced the gaseous sulfur evolved. Also, a slight reduction in the sulfur content of the tar was noticed. $\mathrm{MgO}$ had little effect on gaseous sulfur evolution.

Effect of temperature on sulfur transformation during combustion of char and ash. To get a further understanding of the transformation mechanism of sulfur compounds in ash and char, the combustion experiment of ash and char which obtained from pyrolysis tests was performed separately. Table 3 shows the relative amount of $\mathrm{SO}_{2}$ emission during combustion of char and ash. It could be seen that the ratio of releasing sulfur of char at 800 and $900^{\circ} \mathrm{C}$ are $76.39 \%$ and $79.79 \%$, while in ash, the ratio are only $46.17 \%$ and $55.59 \%$ respectively. It indicates that the sulfur captured in ash will release less sulfurous pollutants during the CFB combustion of polygeneration process.

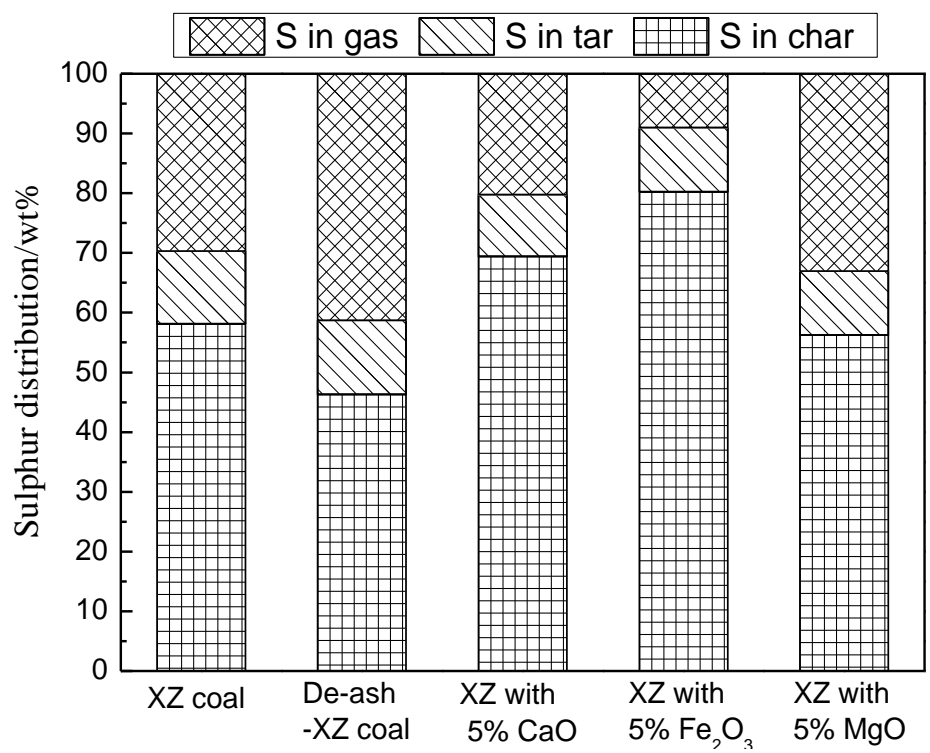

Fig. 6. Sulfur distribution of XZ coal, De-ash-XZ coal and added inorganic matter coal

TABLE $3 \mathrm{SO}_{2}$ Emission During Combustion Of Char And Circulating Ash

\begin{tabular}{llll}
\hline $\begin{array}{l}\text { Combustion } \\
\text { temperature }\end{array}$ & $\mathbf{8 0 0}{ }^{\boldsymbol{}} \boldsymbol{C}$ & $\mathbf{8 5 0}^{\boldsymbol{O}} \boldsymbol{C}$ & $\mathbf{9 0 0}{ }^{\boldsymbol{}} \boldsymbol{C}$ \\
\hline $\mathrm{S}_{\mathrm{SO} 2} / \mathrm{S}_{\mathrm{t}}$ of char & $76.35 \%$ & $78.89 \%$ & $79.79 \%$ \\
$\mathrm{~S}_{\mathrm{SO} 2} / \mathrm{S}_{\mathrm{t}}$ of ash & $46.17 \%$ & $47.63 \%$ & $55.59 \%$ \\
\hline
\end{tabular}

\section{B) Mathematical model results}

Internal temperature distribution of coal particles. The internal temperature distribution of large coal particles versus bed height is shown in Fig. 7. In the heating process, the convection and radiation of ash and pyrolysis gas increase the surface temperature of the large coal particles very rapidly, while the internal temperature of the coal is relatively slow. As the coal and ash moving downwards in the pyrolyzer, the temperature difference between the surface and central of the coal particle expands first and then narrows. This can be considered as a result of thermal resistance in the coal particles, which make a certain delay of the internal temperature.

Temperature distribution of gas-ash-external layer of coal versus bed height. From Fig. 8 , it can be seen that the temperature of pyrolysis gas and circulating ash is always close, which is mainly due to the strong convection effect between them. In the process of transferring heat to the coal surface, the temperature of circulating ash and pyrolysis gas decline smoothly rather than rapidly. A major reason is that, the thermal resistance makes heat conductivity inside the coal particles become the rate-determining step [15], then a slow heat transfer rate from ash and gas to the coal surface appears. 


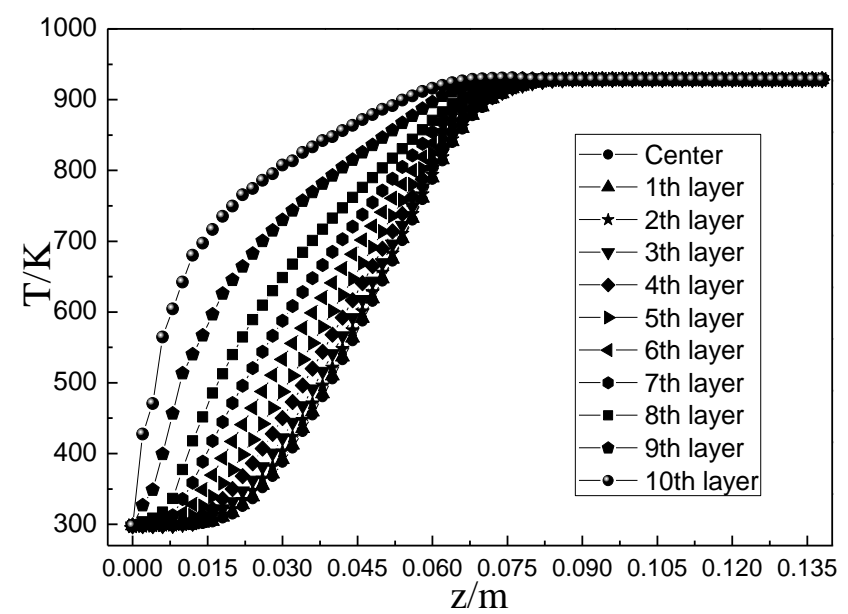

Fig. 7. The internal temperature distribution of large coal particles versus bed height.

$\left(\mathrm{D}=5 \mathrm{~mm}, \mathrm{~T}_{\mathrm{a} 0}=1200 \mathrm{~K}, \mathrm{u}_{\mathrm{s}}=0.125 \mathrm{~m} / \mathrm{min}\right.$, blending ratio of ash to coal $6.0, \beta=0.5, \chi=0.5$ ).

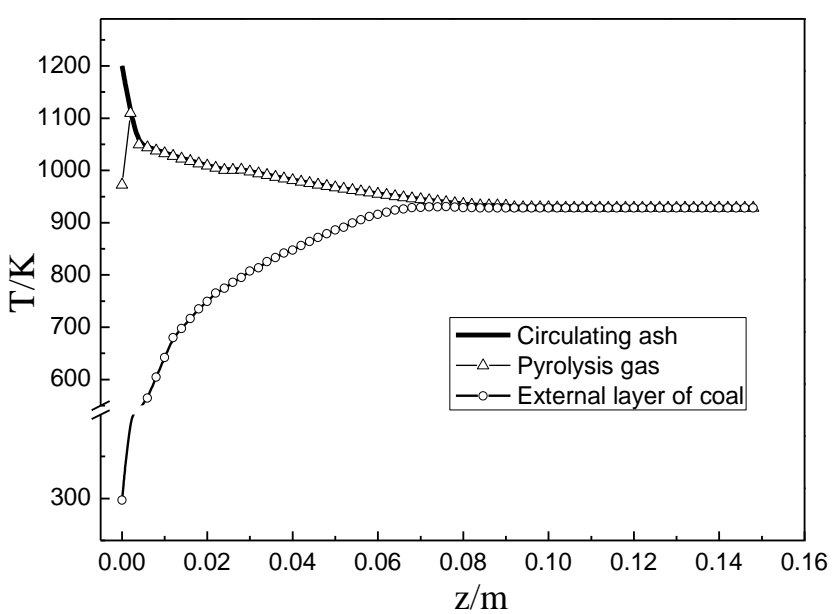

Fig. 8. Temperature distribution of pyrolysis gas-circulating ash-external layer of coal versus bed height. (The same reaction conditions as in Fig. 7).

Local volatile yields and devolatilization rate of a large coal particle versus pyrolysis time. As shown in Fig. 9, the local volatile devolatilization rate first increase and then decrease with pyrolysis time. A layer closer to the center of coal particle has a higher but later peak value of the devolatilization rate. It is suspected that the internal temperature distribution may account for the later peak. Different from the temperature rising process, the devolatilization process of the coal surface do not start until a transient heating process $(\sim 3.8 \mathrm{~s})$.

\section{CONCLUSION}

The distribution and conversion characteristics of sulfur in the polygeneration process of $\mathrm{XZ}$ high-sulfur coal was carried out by coupling the moving bed coal pyrolysis with CFB combustion. A mathematical pyrolysis model of nonisothermal coal particles by circulating ash carrier toward the axial dimension of the moving bed is also developed. The major conclusions are summarized as follows:

Circulating ash had a strong effect on gaseous sulfur retention. The quantity of sulfur fixed in the ash increased with an increase in temperature and a decrease in ash particle size. When the char and circulating ash were combusted in a fixed bed reactor, sulfur fixed in the circulating ash emitted lower quantities of $\mathrm{SO}_{2}$ compared to the quantity of sulfur remaining in the char. The major sulfur-capturing agents in the circulating ash were $\mathrm{CaO}$ and $\mathrm{Fe}_{2} \mathrm{O}_{3}$. XRD results demonstrated that the sulfur captured by $\mathrm{CaO}$ and $\mathrm{Fe}_{2} \mathrm{O}_{3}$ in the circulating ash during pyrolysis was converted into $\mathrm{CaS}$ and FeS. For the large coal particle pyrolysis, heat transfer is the rate-determining step. The devolatilization process has a transient delay compared with the heating process. The temperature of pyrolysis gas is close tothe circulating ash rather than the coal. The present study will aid in improving desulfurization level and provide theoretical prediction data for of coal pyrolysis/CFB combustion grading conversion technology.

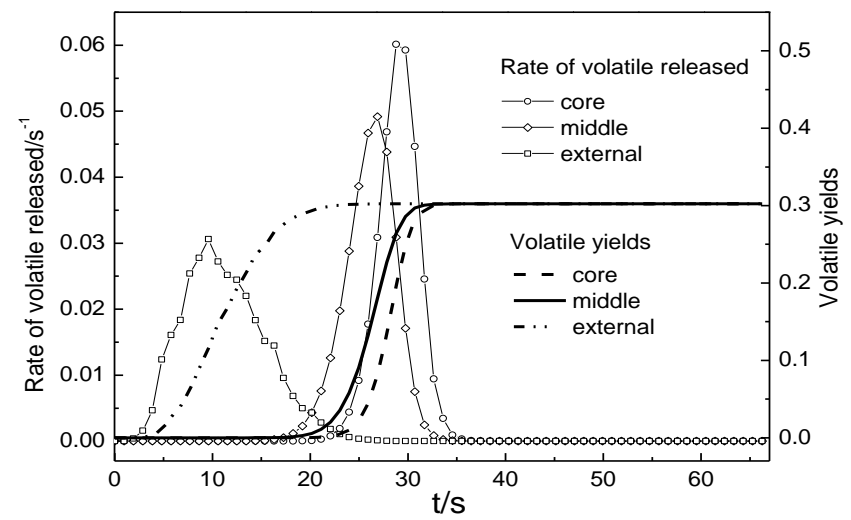

Fig. 9. Local volatile yields and devolatilization rate versus pyrolysis time. (The same reaction conditions as in Fig. 7).

\section{ACKNOWLEDGEMENT}

The work was supported by the National Natural Science Foundation of China (Grant Nos. 21376142).

\section{REFERENCES}

[1] Xuan Qu, Peng Liang, Zhifeng Wang, Rong Zhang, Dongkai Sun, Xiukui Gong, Zhongue Gan, Jicheng Bi. Pilot development of polygeneration process of circulating fluidized bed combustion combined with coal pyrolysis, Chemical Engineering \& Technology [J], 2011.

[2] Morgan Eriksson, Mohammad R. Golriz. Radiation heat transfer in circulating fluidized bed combustors, International Journal of Thermal Sciences [J], 2005.

[3] Peng Liang, Zhifeng Wang, Jicheng Bi. Process characteristics investigation of simulated circulating fluidized bed combustion combined with coal pyrolysis, Fuel Processing Technology [J], 2007.

[4] Peng Liang, Xuan Qu, Zhifeng Wang, Jicheng Bi. Development of CFB (circulating fluidized bed) combustion/coal pyrolysis multiple cogeneration processes, Journal of Engineering for Thermal Energy \& Power [J], 2010.

[5] Rong Xiong, Li Dong, Jian Yu, Xiaofang Zhang, Ling Jin, Guangwen Xu. Fundamentals of coal topping gasification: Characterization of pyrolysis 
topping in a fluidized bed reactor, Fuel Processing Technology [J], 2010

[6] Semra Karaca. Desulfurization of a Turkish lignite at various gas atmospheres by pyrolysis. Effect of mineral matter, Fuel [J], 2003.

[7] Quanrun Liu, Haoquan Hu, Qiang Zhou, Shengwei Zhu, Guohua Chen. Effect of mineral on sulfur behavior during pressurized coal pyrolysis, Fuel Processing technology [J], 2004.

[8] Kuanrong Qiu, Oliver Lindqvist, Tobias Mattisson. Oxidation behaviour of desulphurization residues from gasification and fuel-rich combustion, Fuel [J], 1999.

[9] Guoxin Hu, Haojie Fan, Yaqin Liu. Experimental studies on pyrolysis of Datong coal with solid heat carrier in a fixed bed, Fuel Processing Technology [J], 2001.

[10] Guoxin $\mathrm{Hu}$, Xiwu Gong, Hao Huang, Haojie Fan, Zheng Wang. Experimental studies on flow and pyrolysis of coal with solid heat carrier in a modified rotating cone reactor, Chemical Engineering and Processing
[J], 2008.

[11] Xunliang Liu, Gan Wang, Gang Pan, Zhi Wen. Numerical analysis of heat transfer and volatile evolution of coal particle, Fuel [J], 2013.

[12] C.A. Heidenreich, H.M. Yan, D.K. Zhang. Mathematical modelling of pyrolysis of large coal particles-estimation of kinetic parameters for methane evolution, Fuel [J], 1999.

[13] Peng Liang, Zhifeng Wang, Jicheng Bi. Simulation of coal pyrolysis by solid heat carrier in a moving-bed pyrolyzer, Fuel [J], 2008.

[14] Qiuxiang Yao, Meili. Du, Shuili Wang, Jing Liu, Jianli Yang, Haitao Shang. Distribution of sulfur forms in low temperature pyrolysis of coal, Advanced Materials Research [J], 2012.

[15] Binhang Yan, Yi Cheng, Yong Jin, Cliffyi Guo. Analysis of particle heating and devolatilization during rapid pyrolysis in a thermal plasma reactor, Fuel Processing Technology [J], 2012. 